\title{
WIC Participants’ Perceived Behavioral Control, Attitudes Toward, and Factors Influencing Behavioral Intentions to Redeeming Cash-Value Vouchers at Certified Farmers Markets
}

\author{
Leslie McDonnell $^{1}$, Michelle Neyman Morris ${ }^{2}$, Julie Holland ${ }^{2}$ \\ ${ }^{1}$ Glenn County Health Services WIC \\ ${ }^{2}$ California State University, Chico. Department of Nutrition and Food Science
}

\begin{abstract}
Background: The California Supplement Nutrition Program Women, Infants and Children (WIC) offer a Cash-Value (CV) voucher for the purchase of fresh fruits and vegetables that can be used at Certified Farmers' Markets (CFM). Purpose: The purpose of this study was to identify factors associated with redeeming WIC CV vouchers at (CFM) among English and Spanish speakers. Methods: This was a cross-sectional study; in which Theory of Planned Behavior constructs were included in a self-report survey. Data were collected from women $(n=252)$ at three rural northern California WIC clinics for two weeks. Results: Proportionately more Spanish speakers had greater perceived behavioral control for redeeming CV vouchers at CFM. Not enough variety of produce offered $(\mathrm{p}<0.001)$, not knowing what produce to buy $(p=0.038)$, and unfavorable weather conditions $(p<0.001)$ were proportionately lower among English speakers than Spanish speakers. Proportionately more Spanish speakers identified availability of organic produce $(\mathrm{p}<0.001)$, other items for sale than just produce $(\mathrm{p}<0.001)$, and entertainment provided $(\mathrm{p}<0.001)$ as a factor to redeem CV vouchers. Approximately $43 \%$ of English speakers identified unfavorable weather as a barrier to attend CFM. Conclusion: WIC educators and market managers may use the benefits and barriers identified by ethnic groups to develop interventions that encourage WIC participants to redeem CV vouchers at CFM.
\end{abstract}

(c) 2014 Californian Journal of Health Promotion. All rights reserved.

Keywords: WIC, Certified Farmers' Market, rural, fruits and vegetables, Theory of Planned Behavior, Cash-Value vouchers

The Special Supplemental Nutrition Program for Women, Infants and Children (WIC) provides Cash-Value (CV) vouchers for specific nutritious foods, nutrition education and breastfeeding support for low-income pregnant or post-partum women, and children up to five years of age (U.S. Department of Agriculture (USDA), 2011a; USDA, 2011b). In October 2009, a landmark change to the WIC food package was the addition of a CV voucher for women and children to purchase fresh fruits and vegetables (USDA, 2011a). The monthly cash value of vouchers available to participants is ten dollars for women and six dollars for children one to five years of age. The CV vouchers are commonly redeemed at WIC approved retail stores (USDA, 2011a). Prior to the food package change, carrots were the only fresh produce item that was provided in the monthly food package and only for exclusively breastfeeding mothers (USDA, 2011a; Committee to Review the WIC Food Packages, 2005). The only other option to receive fresh produce through the WIC program was participating in the seasonal Farmers' Market Nutrition Program (FMNP) (USDA, 2011c).

Unlike the monthly issued fruit and vegetable $\mathrm{CV}$ voucher, there is a limited number of seasonal FMNP checks available and not every family is guaranteed FMNP checks due to funding constraints. By mid-2010, six California WIC locations completed a successful pilot of Certified Farmers' Markets (CFM) vendors accepting WIC participants' fruit and vegetable $\mathrm{CV}$ vouchers. Subsequently, California WIC 
offered the opportunity to 13 additional CFM vendors, including a Glenn County CFM, a neighboring county to Butte, the focus of the current study. Glenn County has a population of less than 29,000 and is comprised largely of farming communities (U.S Census Bureau, 2011). Glenn County WIC office served 1,522 participants as of December 2010 (Integrated Statewide Information System (ISIS) database software, California WIC, 2011) and had participated in the seasonal FMNP for 12 years.

At the time of the study, to the authors' knowledge, there were no known publications on redeeming CV vouchers at CFM. A previous study found that food purchasing can vary by ethnicity, such as Hispanics purchasing proportionately more fruits and vegetables than African Americans, and proportionately less mixed dishes than Whites (Cullen et al., 2007). Neuhouser, Thompson, Coronado and Solomon (2004) found that Hispanics consumed more fruits and vegetables than non-Hispanic Whites, and that highly acculturated Hispanics consumed fewer fruits and vegetables than those less acculturated. This finding is relevant because Glenn County WIC provides nutrition education in English and Spanish. There is increasing interest among health professionals and institutions in encouraging fruit and vegetable consumption to improve health, especially among lower socioeconomic populations which tend to have poorer intakes (Cassady, Jetter \& Culp, 2007). We wish to identify criteria to include in nutrition education messages to encourage WIC participants utilizing their fruit and vegetable $\mathrm{CV}$ vouchers at CFM.

This study used the Theory of Planned Behavior (TPB) to assess the perceived behavioral control, attitudes toward, and factors influencing intentions of WIC participants to using fruit and vegetable $\mathrm{CV}$ vouchers at CFMs. The theory is based on the assumption that most behaviors of social relevance are under volitional control (Glanz, Rimer \& Viswanth, 2008). Most notably is behavioral intention, the precursor of behavior. The three constructs that have direct influence over intention are: attitudes toward behavior, subjective norm and perceived behavioral control over behavior (Glanz et al.,
2008). The theory suggests that when individuals have a sufficient degree of control over their behavior and have a positive attitude about a behavior, they are likely to carry out the intended behavior when the opportunity is presented (Glanz et al., 2008). It is theorized that WIC participants, who are sufficiently motivated by positive attitudes and intentions toward redeeming $\mathrm{CV}$ vouchers at CFM, will be more likely to redeem $\mathrm{CV}$ vouchers for fruits and vegetables at CFM. We hypothesized that more WIC Spanish speakers will have greater perceived behavioral control, positive attitudes, and intentions to using Cash-Value vouchers at CFM than English speakers.

\section{Methods}

\section{Study Design and Sample}

This study was a cross-sectional survey of WIC participants. At the time of the study, Glenn County WIC participants were primarily Hispanic (75.4\%), with non-Hispanic White participants representing approximately $22 \%$ of the WIC population, and the remaining 2\% comprised of Asian/Asian Americans, Native Americans, African Americans and Pacific Islanders (ISIS database software, California WIC, November 17, 2010 ). Inclusion criteria were current enrollment in the Glenn County WIC program at Hamilton City, Orland or Willows, and being 18 years of age or older. Informed consent was obtained prior to participation in the study. All participants were offered an incentive gift such as a water bottle, cookbook or pedometer after completing the survey, and they were also entered into a raffle for a gift certificate that was issued at the completion of data collection. All procedures were approved by the California State University, Chico Human Subjects Review Committee.

At the time of data collection, there were approximately 627 families in Glenn County participating in WIC. A sample size table determined that approximately 240 ( $\mathrm{CI}=95 \%$, $\mathrm{p}=0.05$ ) surveys were necessary to detect the effect sizes desired; however, 265 surveys were collected to account for attrition and incomplete surveys. Modified systematic random sampling 
was employed to contact WIC clients to participate in the study. A master list was created identifying all WIC participants in Glenn County by first name alphabetically. The total number of WIC participants was divided by the desired sample size to obtain a sampling fraction of three, then every third WIC participant was called on the list. In addition, to ensure reaching the target number of surveys required within the two-week data collection period, WIC participants $(\mathrm{n}<30)$ attending regularly scheduled-appointments at one of the two clinics Hamilton City and Orland were also asked to participate in the study. Recruitment took place the first two weeks of February 2011.

\section{Measures and Data Collection}

Survey questions were developed by Glenn County WIC staff and nutrition educators, and based on factors identified during literature review (Kunkel, Luccia \& Moore, 2003; Middleton \& Smith, 2011; Racine, Smith Vaughn \& Laditka, 2010) and WIC participant responses on the use of the seasonal FMNP checks at CFM. The survey was founded on the Theory of Planned Behavior and focused on perceived behavioral control, attitudes toward the behavior, and factors influencing intentions.

Table 1

Demographic Characteristics of the Sample by Language Preference

\begin{tabular}{|c|c|c|c|c|c|c|c|}
\hline & \multicolumn{2}{|r|}{ All } & \multicolumn{2}{|c|}{ Spanish speakers } & \multicolumn{2}{|c|}{ English speakers } & \multirow[b]{2}{*}{ P-value } \\
\hline & $\mathrm{n}$ & $(\%)$ & $\mathrm{n}$ & $(\%)$ & $\mathrm{n}$ & $(\%)$ & \\
\hline Age, mean (SD)* & 248 & $29.2 \pm 6.5^{*}$ & 115 & $31.0 \pm 6.5^{*}$ & 133 & $27.7 \pm 6.2^{*}$ & $<0.001$ \\
\hline \multicolumn{8}{|l|}{ Ethnicity $(n=251)$} \\
\hline Hispanic & 194 & 77.3 & 118 & 100 & 76 & 57.1 & $<0.001$ \\
\hline Non-Hispanic & 57 & 22.7 & 0 & 0 & 57 & 42.9 & \\
\hline \multicolumn{8}{|l|}{ Education level $(n=248)$} \\
\hline High school/ less & 184 & 74.2 & 107 & 92.2 & 77 & 58.3 & $<0.001$ \\
\hline Some college/ higher & 64 & 25.8 & 9 & 7.8 & 55 & 41.7 & \\
\hline \multicolumn{8}{|l|}{ Employment or in school $(n=252)$} \\
\hline Unemployed/ not in school & 152 & 60.3 & 84 & 70.6 & 68 & 51.1 & 0.002 \\
\hline Employed/ going to school & 100 & 39.7 & 35 & 29.4 & 65 & 48.9 & \\
\hline \multicolumn{8}{|l|}{ Marital Status $(n=249)$} \\
\hline Married or living with partner & 212 & 85.1 & 102 & 87.9 & 110 & 82.7 & 0.248 \\
\hline Not married or living with partner & 37 & 14.9 & 14 & 12.1 & 23 & 17.3 & \\
\hline \multicolumn{8}{|l|}{ Household size $(n=251)$} \\
\hline $1-2$ & 13 & 5.2 & 6 & 5.1 & 7 & 5.3 & 0.009 \\
\hline 3- 4 & 140 & 55.8 & 53 & 44.9 & 87 & 65.4 & \\
\hline $5-6$ & 74 & 29.5 & 44 & 37.3 & 30 & 22.6 & \\
\hline 7 or more & 24 & 9.6 & 15 & 12.7 & 9 & 6.8 & \\
\hline \multicolumn{8}{|l|}{ Annual Income $(n=220)$} \\
\hline Less than $\$ 10,000$ & 41 & 18.6 & 11 & 10.7 & 30 & 25.6 & 0.038 \\
\hline$\$ 10,000-\$ 19,999$ & 56 & 25.5 & 26 & 25.2 & 30 & 25.6 & \\
\hline$\$ 20,000-\$ 29,999$ & 75 & 34.1 & 42 & 40.8 & 33 & 28.2 & \\
\hline$\$ 30,000-\$ 40,000$ & 39 & 17.7 & 21 & 20.4 & 18 & 15.4 & \\
\hline greater than $\$ 40,000$ & 9 & 4.1 & 3 & 2.9 & 6 & 5.1 & \\
\hline
\end{tabular}

The survey included 69 questions and took approximately 15 to 18 minutes to complete. Data were collected on past seasonal FMNP check use, history of CFM patronage and demographic data (Table 1); question responses were close-ended and included an option of "I don't know”. Twelve questions were developed to address perceived behavioral control in redeeming WIC monthly fruit and vegetable CV vouchers at CFM. Likert-scale responses for perceived behavioral control questions were: "it would stop me," "it might stop me" and "it wouldn't stop me” (Table 2). Likewise, to address attitude toward redeeming $\mathrm{CV}$ vouchers at CFM; Likert-scale responses for 13 questions were: "not important," "somewhat important," 
and “important" (Table 3). Lastly, responses for the 12 questions on factors influencing behavioral intentions were: "not likely," "somewhat likely" and "likely" (Table 4).

Table 2

WIC Participants’ Perceived Behavioral Control to Redeeming Cash-Value Vouchers at Certified Farmers' Markets (Ordinal Regression $\left.{ }^{\mathrm{a}}\right)^{\mathrm{b}}$

\begin{tabular}{lrrrrrrr}
\hline & \multicolumn{2}{c}{ All participants } & \multicolumn{2}{c}{ Spanish speakers } & \multicolumn{2}{c}{ English speakers } & p-value \\
\hline & $\mathrm{n}$ & $\%$ & $\mathrm{n}$ & $\%$ & $\mathrm{n}$ & $\%$ & \\
\hline Not enough variety of produce offered & & & & & & & $<0.001$ \\
$\quad$ would stop me & 49 & 19.4 & 25 & 21.0 & 24 & 18.0 & \\
$\quad$ might stop me & 57 & 22.6 & 8 & 6.7 & 49 & 36.8 & \\
$\quad$ would not stop me & 146 & 57.9 & 86 & 72.3 & 60 & 45.1 & \\
$\quad$ Not knowing what produce I can buy & & & & & & & 0.038 \\
$\quad$ would stop me & 24 & 9.5 & 15 & 12.6 & 9 & 6.8 & \\
$\quad$ might stop me & 30 & 11.9 & 3 & 2.5 & 27 & 20.3 & \\
$\quad$ would not stop me & 198 & 78.6 & 101 & 84.9 & 97 & 72.9 & \\
Unfavorable weather conditions & & & & & & & \\
$\quad$ would stop me & 67 & 26.8 & 22 & 18.5 & 45 & 33.8 & $<0.001$ \\
$\quad$ might stop me & 57 & 22.8 & 8 & 6.7 & 49 & 36.8 & \\
$\quad$ would not stop me & 126 & 50.4 & 89 & 74.8 & 37 & 27.8 & \\
\hline
\end{tabular}

${ }^{a}$ Education (high school or less/Some college or more) and seasonal Farmers' Market Nutrition Program participation (yes/no) were added as control variables in multivariate analyses. Ethnicity (Hispanic/non-Hispanic) was omitted from analyses due to being highly correlated with language preference (Spanish/English).

${ }^{b}$ The following variables were not significantly different between Spanish and English speakers: the wrong time of day, the wrong day of the week, the distance to the CFM, difficulty finding parking, no transportation service provided, only seasonally grown produce is sold, not selling frozen/canned foods, ease of buying foods at grocery store, produce does not look clean or not packaged.

The survey was written in English, translated into Spanish and then translated back into English by employees at the California WIC Division. Spanish was the primary language of the translators. Glenn County WIC staff was trained on interviewing, data collection techniques and use of the online survey tool that was utilized, Survey Monkey®. The trained interviewers field tested the survey via face-toface interviews at the neighboring Butte County WIC clinic ( $\mathrm{n}=30$ participants); the participants were asked about the clarity of the survey questions. The survey was revised based on participant responses and suggestions.

\section{Statistical Tests}

IBM SPSS Statistics (version 21, IBM Corporation, NY 2012) was used to analyze data. Means, standard deviations, percentages and frequencies were computed for demographic variables. Chi-square analyses and independentsample t-tests were used to compare demographic data between English and Spanish speakers (Table 1). Dependent variables were the behavioral control, attitudes towards the behavior, and factors influencing behavioral intention to using $\mathrm{CV}$ vouchers at CFM by the study participants; see left column on Tables 2, 3 and 4. Because the dependent variables had three-point Likert scales, ordinal regression was employed in multivariate analyses. The two variables 'educational level' and 'employment/in school' were highly correlated with each other, so employment/in school variable was omitted from multivariate analyses. Despite differences in household size and annual income between English and Spanish speakers, these variables were not entered into analyses, since all study participants met the low-income qualification to enroll in WIC. Language preference was the main independent variable of interest; accordingly, proportions were reported for the dependent variables between English speakers and Spanish speakers. Language preference (English/Spanish), FMNP participation (participant/nonparticipant) and 
education (high school or less/some college or more) were factored simultaneously in the ordinal regression analyses. These analyses were used to calculate significant proportional differences in dependent variables to using $\mathrm{CV}$ vouchers at CFM between English speakers and Spanish speakers. Ethnicity (Hispanic/nonHispanic) was omitted from analyses due to its high association with language preference. Statistical significance was set at $\mathrm{p} \leq 0.05$.

Table 3

WIC Participants’ Attitudes Towards Redeeming Cash-Value Vouchers at Certified Farmers' Markets (Ordinal Regression $\left.{ }^{\mathrm{a}}\right)^{\mathrm{b}}$

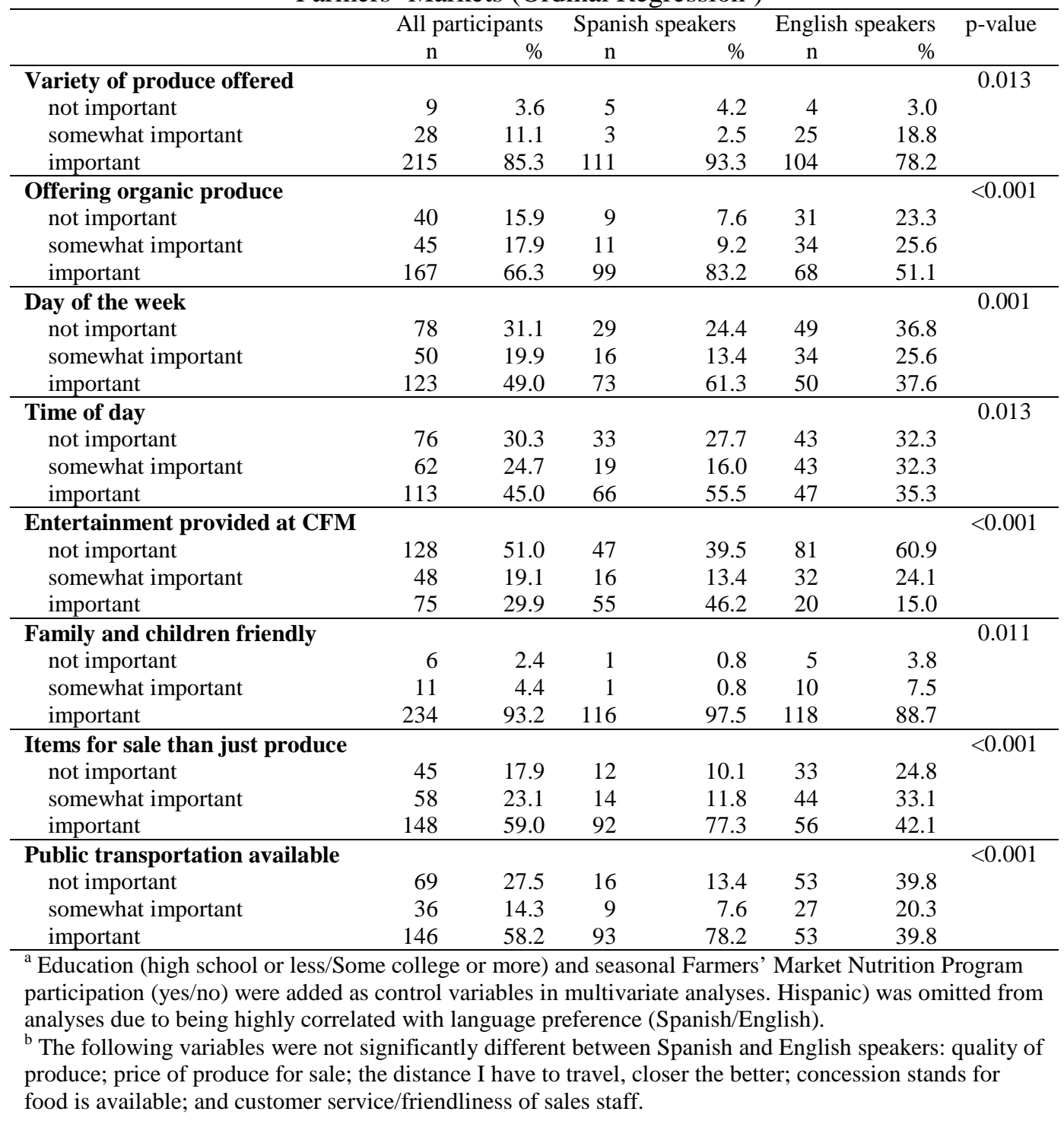

\section{Results}

\section{Sample Characteristics}

All Spanish speakers self-identified as Hispanic, but English speakers were Hispanic or nonHispanic. The mean age of the study participants was $29.2 \pm 6.5$ years (range: $18-55$ years). Most participants were English speakers (Table 1). Proportionately, more English speakers had attended college $(\mathrm{p}<0.001)$, and had incomes less than $\$ 20,000$ annually $(p=0.005)$. There were no significant differences in marital status between English and Spanish speakers. 


\section{Perceived Behavioral Control to Using Cash- Value Vouchers at CFM}

Logistic ordinal regression results indicated that three factors on perceived behavioral control to overcome barriers were significantly different between English and Spanish speakers (Table 2). The answers of not enough variety of produce offered $(\mathrm{p}<0.001)$, not knowing what produce to buy $(\mathrm{p}=0.038)$, and unfavorable weather conditions $(p<0.001)$ were proportionately lower among English speakers than Spanish speakers. Proportionately more study participants with HS or less $(71.7 \%)$ than participants with some college or more $(43.8 \%)$ thought that wrong time of day would not stop them in using CV vouchers at CFM, while controlling for education and language preference $(\mathrm{p}=0.024)$.

\section{Attitude towards the Using Cash-Value Vouchers at CFM}

Logistic ordinal regression results indicated that, proportionately fewer English speakers than Spanish speakers indicated that the following factors were associated with their intentions to buy produce at CFMs: variety of produce $(p=0.011)$, offering organic produce $(p=0.002)$, day of the week $(p=0.031)$, entertainment provided ( $\mathrm{p}=0.002)$, family and children friendly $(p=0.003)$, other items for sale than just produce $(\mathrm{p}=0.001)$, and availability of public transportation $\quad(\mathrm{p}<0.001) \quad$ (Table 3). Proportionately fewer FMNP participants (46.3\%) than non-participants (65.1\%) thought that having other items for sale than just produce was important in using $\mathrm{CV}$ vouchers at CFM, while controlling for education and language preference $\quad(\mathrm{p}=0.016)$. FMNP participants (45.1\%) than non-participants (64.5\%) thought that having public transportation was important in using $\mathrm{CV}$ vouchers at CFM, while controlling for education and language preference $(\mathrm{p}<0.001)$.

\section{Factors Associated with Behavioral Intention toward Using Cash-Value Vouchers at CFM}

Logistic ordinal regression results indicated that, proportionately more Spanish speakers than English speakers were likely to use CV vouchers for the following variables: 'I would be helping out farmers or community' ( $\mathrm{p}=0.005$ ), 'produce is grown in season' $(\mathrm{P}<0.001)$, 'I like shopping outdoors' $\quad(p=0.005), \quad$ 'I like supporting sustainable practices’ ( $\mathrm{p}=0.003)$ (Table 4). Proportionately more study participants with HS or less $(62.3 \%)$ than some college or more (48.4\%) thought it was important that 'if public transportation was available' in redeeming CV vouchers at CFM, while controlling for language preference and ethnicity $(\mathrm{p}=0.002)$. Proportionately more study participants with HS or less $(65.5 \%)$ than some college or more (37.5\%) thought that 'I can buy other food items than just produce' was important in using CV vouchers at CFM, while controlling for language preference and ethnicity (Ordinal Regression, $\mathrm{p}=0.027)$.

\section{Discussion}

The results of this study provide insight into Glenn County WIC participants' perceived behavioral control, attitudes toward, and factors influencing intentions to purchasing fruit and vegetables at CFM with WIC CV vouchers. Spanish speakers were more motivated to redeem $\mathrm{CV}$ vouchers if criteria deemed important (variety of produce, offering organic produce, day of the week, entertainment provided, family and children friendly, other items for sale than just produce, availability of public transportation) were met and English speakers were significantly less motivated to redeem fruit and vegetable if perceived barriers existed. Barriers to not redeeming CV vouchers at CFM for English speakers were not enough variety of produce offered, not knowing what produce to buy, and unfavorable weather conditions.

Over 78\% of Spanish speakers considered public transportation important to redeem $\mathrm{CV}$ vouchers at CFM, while less than $40 \%$ of English speakers thought it was important (Table 3). Also, the furthest clinic from the CFM, Willows, was a significant covariate. WIC participants at this site considered the closer distance for travel to the CFM as important for redeeming CV vouchers and considered no transportation service provided as a barrier. Similar to our findings, other studies have identified barriers to shopping at farmers' markets (Racine, Vaughn Smith \& Laditka, 2010; Middleton \& Smith 
2011; Anliker, Winne \& Drake, 1992). Transportation to CFM seems to be a common barrier identified by both older adults and WIC participants enrolled in the seasonal FMNP. Middleton and Smith (2011) reported than transportation issues were barriers to frequenting farmers' markets among older adults participating in the Senior Farmers' Market Nutrition Program. Among WIC participants in the District of Columbia (DC) and North
Carolina, barriers to frequenting farmers' markets included transportation, no farmers' market in close proximity, and not knowing location of the markets (Racine et al., 2010). Anliker, Winne, and Drake (1992) also identified lack of transportation as well as location of markets as barriers to redeeming seasonal FMNP checks at Connecticut farmers' markets.

Table 4

Factors that Influence WIC Participants’ Behavioral Intention to Using Cash-Value Vouchers at Certified Farmers' Markets (Ordinal Regression $\left.{ }^{\mathrm{a}}\right)^{\mathrm{b}}$

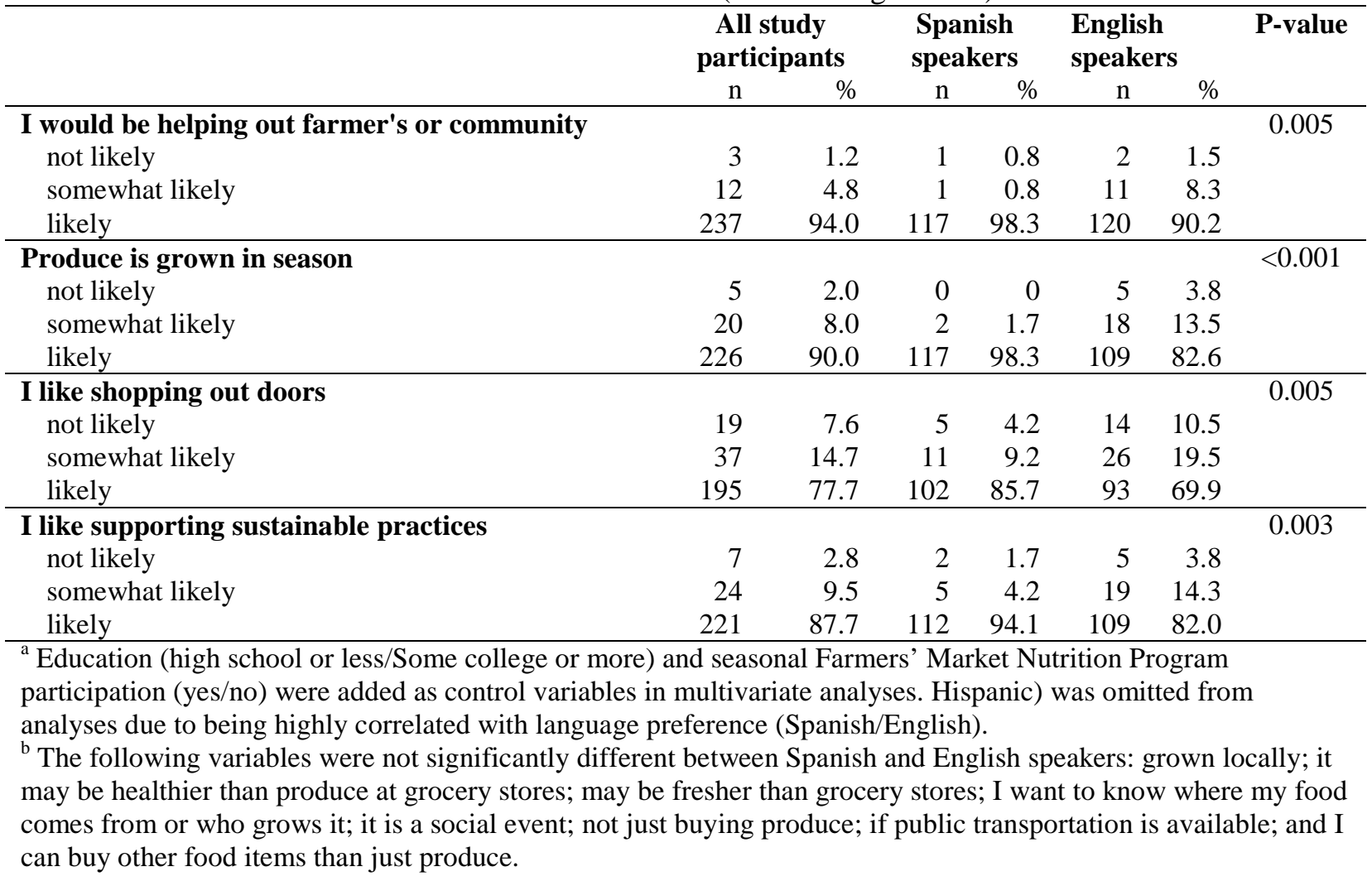

Few studies have assessed produce shopping behaviors among Spanish-speaking families. The Food and Marketing Institute reported that Hispanics favor local produce and are more likely to buy local produce if they earn under \$25,000 a year (Food and Marketing Institute Research 2004). In the current study, attitudes towards attending CFM among Spanish speakers were offering a variety of produce, having offering organic produce, and other items for sale than just produce (Table 3). Proportionately more Spanish speakers thought it was important to have entertainment provided and a family and child CFM. This may reflect how celebrations centered on good food to reinforce relationships among Hispanic families (Food and Marketing Institute, Research 2004; Food and Marketing Institute, 2002). Thus, the social component, in addition to the availability of fruit and vegetables for purchase may 
encourage shopping at CFM and redeeming CV vouchers.

Studies have documented that individuals with more education are more likely to frequent farmers' markets (Blanck, Thompson, Nebeling \& Yaroch, 2011; Kropf et al., 2007; Centers for Disease Control and Prevention, 2010). Kropf (2007) also noted that women participating in WIC FMNP in Ohio had higher education levels (high school graduate versus non-high school graduate) than those who did not participate. This may be related to our findings that participants with a high school diploma or less thought it more important to have public transportation and other items than just produce for sale. In contrast, we found that participants with lower education would not be stopped by wrong time of day than those with higher education.

Several agencies can promote the use of CV vouchers at CFM. Educators have the opportunity to inform/educate vulnerable populations about the healthful benefits of eating fruits and vegetables whereas market managers can increase sales for their produce vendors with increased redemption of WIC CV vouchers. Policy makers have the opportunity to partner with market managers, health educators, WIC staff and participants to coordinate services. There was a high frequency of agreement among Spanish and English speakers regarding perceived behavioral control, attitudes toward, and factors influencing intentions to redeeming $\mathrm{CV}$ vouchers at CFM. Similarities should be acknowledged in order to promote increased participation among WIC participants at CFM in a cost effective manner. Varied and regional marketing strategies may be required to ensure equal participation from English and Spanish speakers to attend CFM. Examples of marketing strategies may be: offering WIC information booth; offering bus coupons or free transportation; offering non-produce items for sale; scheduling entertainment such as music, cooking demonstrations and activities for children; offering affordable organic produce and electronic banking services.
This study included mixed sampling methods ( $n=30$ convenience, and $n=222$ random), and sampling in a rural setting, thus limiting the generalizability of the results to WIC participants throughout California and the US. Additionally, language preference, English/Spanish, was used as a proxy for acculturation. The authors utilized California WIC program's questions on race and ethnicity which does not clarify the nation of origin for Hispanic ethnicity nor acculturation level. However, the sample distribution for Hispanics in northern California is similar to the WIC program statewide (Food and Nutrition Service 2002). This study is pioneering a subject where little or no research has been published. WIC staff, market managers and policy makers can use this information to help minimize barriers for WIC participants in redeeming their CV vouchers at CFM. The survey was not tested for reliability, and it did not ask if the dollar amount on the CV voucher was considered a barrier or a benefit (\$10 increments for adults and $\$ 6$ for children) and should be included in future studies.

\section{Implications for Research and Practice}

WIC nutritionists have an opportunity to provide participants with specific regional CFM information that could help with purchasing decisions. WIC classes could focus on factors associated with using CV vouchers at CFM, such as teaching WIC participants how to identify, select and prepare 'locally sold' produce at CFM. Educational messages during WIC classes could include seasonally grown produce offered, outdoor shopping experience, how shopping with CV vouchers at CFM differs from retail shopping experience and 'what are' sustainable growing practices'. Additionally, despite statistical differences between English and Spanish speakers, agreement was found between the two groups.

The new WIC CV voucher has potential for financially supporting farmers of locally grown produce. CFM popularity was observed in the California WIC community by increases in seasonal FMNP redemption rates over the last several years (2005: 57.21\% to 2012: 66.16\%) (Griffin P, written communication, 2013). 
Millions of dollars of WIC CV vouchers are issued each month for the purchase of fruits and vegetables nationwide which are commonly redeemed at retail stores. California WIC alone issues well over 7 million dollars each month (Cowell T, written communication, 2009). Communities have the opportunity to keep the revenue from WIC CV vouchers local by encouraging WIC participants to visit and purchase produce using their $\mathrm{CV}$ vouchers at CFM. With the availability of WIC fruit and vegetable $\mathrm{CV}$ vouchers and the growth and popularity of farmers' markets nationwide, further studies are warranted among other WIC populations in order to maximize $\mathrm{CV}$ voucher redemption rates at CFM.

\section{Acknowledgements}

The authors would like to thank Glenn County and Butte County WIC staff for their assistance with this study. Data for this manuscript were taken from a thesis for one of the authors (LM). The California State University, Chico provided funding for use of Survey Monkey ${ }^{\circledR}$. LM and JS dedicate this manuscript to memory of their parents who passed during the preparation of this

\section{References}

Anliker, J. A., Winne, M., \& Drake, L. T. (1992). An evaluation of the Connecticut Farmers' Market Nutrition Program. Journal of Nutrition Education, 24(4), 185-191.

Blanck, H. M., Thompson, O. M., Nebeling, L., \& Yaroch, A. L. (2011). Improving fruit and vegetable consumption: use of farm-to-consumer venues among US adults. Prevention of Chronic Disease, 8(2), A49.

Cassady, D., Jetter, K., \& Culp, J. (2007). Is price a barrier to eating more fruits and vegetables for lowincome families? Journal of the American Dietetic Association, 107(11), 1909-1915.

Centers for Disease Control and Prevention. (2010). State specific trends in fruit and vegetable consumption among adults-United States, 2000-2009. Morbidity and Mortality Weekly Report, 59(35), 1125-1130.

Committee to Review the WIC Food Packages. (2005) WIC food packages: Time for a change. Washington, DC: The National Academies Press.

Cullen, K., Baranowski, T., Watson, K., Nicklas, T., Fisher, J., O’Donnell, S., Baranowski, J., Islam, N., \& Missaghian, M. Food category purchases vary by household education and race/ethnicity: Results from grocery receipts. Journal of the American Dietetic Association, 107(10), 1747-1752.

Food and Marketing Institute. (2002). Hispanics bring together family and food. Supermarket Research. 4(3), 4.

Food and Marketing Institute Research. (2004). El Mercado 2004: A perspective on U.S. Hispanic shopping behavior. Washington DC. Accessed April 1, 2013, from: http://www.fmi.org/forms/store/CommercePlusFormPublic/search?action=Feature

Food and Nutrition Service. (2002). Funding and Program Data. Table 1 Racial/ethnicity enrollment by region and state April 2002. Accessed December 2, 2011, from: http://www.fns.usda.gov/wic/racialethnicdata/2002table1.htmhttp://www.fns.usda.gov/wic/racial-ethnicdata/2002table1.htm .

Glanz, K., Rimer, B. K., \& Viswanth, K. (2008). Health behavior and health education: theory, research and practice. (4th ed.). San Francisco, CA: Jossey-Bass Publishers.

Kropf, M. L., Holben, D. H., Holcomb, J. P., \& Anderson, H. (2007). Food security status and produce intake and behaviors of Special Supplemental Nutrition Program for Women, Infants, and Children and Farmers’ Market Nutrition Program participants. Journal of the American Dietetic Association, 107(11), 1903-1908.

Kunkel, M. E., Luccia, B., \& Moore, A. C. (2003). Evaluation of the South Carolina Seniors Farmers' Market Nutrition Education Program. Journal of the American Dietetic Association, 103(7), 880883. 
Middleton, C., \& Smith, S. (2011). Purchasing habits of seniors farmers' market shoppers: utilizing the Theory of Planned Behavior. Journal of Nutrition in Gerontology and Geriatrics, 30(3), 248-260.

Neuhouser, M., Thompson, B., Coronado, G., \& Solomon, C. (2004). Higher fat intake and lower fruit and vegetables intakes are associated with greater acculturation among Mexicans living in Washington State. Journal of the American Dietetic Association, 104(1), 51-57.

Racine, E. F., Vaughn Smith, A., \& Laditka, S. B. (2010). Farmers' market use among African-American women participating in the Special Supplemental Nutrition Program for Women, Infants and Children. Journal of the American Dietetic Association, 110(3), 441-446.

U.S. Census Bureau. State and County Quick Facts. Glenn County. (2011). Accessed November 11, 2011, from: http://quickfacts.census.gov/qfd/states/06/06021.html

U.S. Department of Agriculture, Food and Nutrition Service, Office of Research and Analysis. (2011a). WIC Food Packages Policy Options Study, by Cole, N., Jacobson, J., Nichols-Barrer, I., \& Fox, M. K. Alexandria, VA.

U.S. Department of Agriculture, Food and Nutrition Service. Nutrition Program Facts. (2011b). Accessed January 16, 2014, from: http://www.fns.usda.gov/sites/default/files/WIC-Fact-Sheet.pdf

U.S. Department of Agriculture. WIC Farmers’ Market Nutrition Program fact sheet. (2011c). Accessed January 16, 2014, from: http://www.fns.usda.gov/sites/default/files/WIC-FMNP-Fact-Sheet.pdf

Author Information

Leslie McDonnell, MS, RD, IBCLC

At the time of the study, Glenn County Health Services

WIC.

Lead author is currently retired.

Michelle Neyman Morris, PhD, RD

California State University, Chico.

Department of Nutrition and Food Sciences.

*Julie Holland, $\mathrm{PhD}$

California State University, Chico.

Department of Nutrition and Food Sciences.

$400 \mathrm{~W} .1^{\text {st }}$ Street, Chico, CA.

(530) 898-6567, (530) 898-5586 (fax),

jmholland@csuchico.edu.

* corresponding author 